\title{
Implementing competence assessment in university education
}

\author{
A comment on using the Collegiate Learning Assessment as a prototype
}

\author{
Tina Seidel
}

Technische Universität München*

\begin{abstract}
The development of instruments such as the Collegiate Learning Assessment (CLA) requires high expertise in educational assessment as well as methodological and technical rigor. The CLA is based on a clear conceptualization of competence and uses frontline methods. It can therefore serve as a prototype for other areas of competence assessment beyond business education. Measuring university effectiveness is likely to remain a key point on the agenda of university reform. However, assessment of learning outcomes can be effective only if it is combined with appropriate measures for improving performance, such as the systematic training and certification of novice university teachers.
\end{abstract}

Keywords: university education, competence assessment, professional development, teachers

The quality and effectiveness of higher education is a matter of considerable public and policy interest. In Europe, for example, there has been much critical discussion of the Bologna reforms and whether they are succeeding in their stated aims of promoting access for a diversity of students, comparability across educational systems, and quality of education. Since the inception of the reforms, universities have undergone major changes in the composition of their student populations and in the study programs and degree qualifications offered. In most European countries, about 50\% of the student population is now admitted to university education (OECD, 2010). Thus, universities no longer educate a small and highly selective group of students, but cater for students from the upper achievement spectrum with a variety of backgrounds.

Beyond changes in the composition of the student body, learning goals and outcomes are at the heart of the university reforms. Educational systems are switching from an input- to an output-driven approach, with quality of education being judged in terms of the knowledge and skills that students will require in their later professional careers. In this respect, universities are becoming increasingly accountable for

* Tina Seidel, Friedl Schöller Endowed Chair for Teaching and Learning Research, TUM School of Education, Technische Universität München, Germany; tina.seidel@tum.de 
the quality of education provided, and their effectiveness has become a topic of much discussion.

In this context, universities need to decide how to assess effectiveness and to choose indicators and instruments that provide valid and reliable measures. Richard J. Shavelson's contribution to this issue both demonstrates high standards and illustrates the challenges facing educational research in providing such measures. In commenting on his contribution, I will first argue that the Collegiate Learning Assessment (CLA) is an example of methodological and technical rigor in the development of an assessment for use in higher education. In the second part of my comment, I will outline challenges with regard to its implementation. Specifically, I will argue that measuring outcomes can be effective only if assessment is embedded in concepts to improve performance by facilitating change in the educational system. Teachers' professional development is one of the most important levers in educational reform (Desimone, 2009). A focus on university teachers' professional development can therefore help to align curricula and study programs to the desired student learning outcomes.

\section{The Collegiate Learning Assessment as a prototype for competence assessment}

The Collegiate Learning Assessment (CLA) is an example for the application of high standards and methodological and technical rigor in the assessment of student competencies. The CLA is based on a complex definition of competencies as contextspecific cognitive dispositions that are needed to cope with certain situations or tasks in specific domains (Shavelson, in this issue) - in other words, as complex abilities that are relevant for performance in real-life situations.

The construction of the CLA was guided by a set of seven facets representing this definition of competence (Shavelson, this issue), namely:

- targeting complex abilities and skills,

- testing performance,

- using standardization,

- using tasks with high fidelity,

- defining minimum levels of competence,

- including tasks and testing skills that can be developed over time, and

- drawing on personal and social characteristics as a basis that motivates high levels of learning and performance.

The CLA measures complex aspects of undergraduate student learning, such as critical thinking, analytical reasoning, problem solving, and communication. It is based on the principle that university students need to develop complex competencies in their respective fields - competencies that require a deep understanding of the subject matter, meta-cognitive skills, strategies for critical reflection, and emotional and 
motivational development - in order to make complex decisions and to communicate decisions and ideas to heterogeneous audiences. Thus, the competencies assessed by the CLA reflect the key objectives of university programs in many disciplines, including business, medicine, and engineering.

From the psychometric perspective, the CLA uses frontline methods and analysis techniques. For example, the scoring of student responses is based on a systematic rubric. First, human scorers evaluate students' responses. Their scores are then benchmarked and given as input to natural language processing software.

The standards and criteria applied in the CLA have their roots in the early beginnings of educational assessment. As Shavelson (in this volume) points out, «many of the ideas underlying the CLA are not new ... but what makes the CLA new is that is solves past problems of time, cost and scoring by capitalizing on internet, computer, and statistical-sampling technologies». In this respect, the CLA reflects how expertise in educational assessment has developed consistently over time. It therefore has prototype character for future developments in higher education assessment, especially in domains and disciplines that focus on developing complex human abilities.

\section{Challenges for implementing competence assessment in the context of university education}

The CLA represents a major advance in providing universities with tools for assessing their students' major learning outcomes, and is therefore a valuable measure for studying university effectiveness. However, it has long been known that measuring learning outcomes cannot be truly effective unless it is embedded within concepts and measures to facilitate change and improvement in the educational system. Teachers' professional development has been shown to be one of the most important levers for educational reform (Desimone, 2009). In order to implement reforms successfully, however, the existing structures have to be taken into account.

In Germany, for example, the majority of university teachers are rather young and inexperienced scientists who are new to the field of academia (Johannes \& Seidel, 2010). These novices are rarely trained systematically for the demands of university teaching - rather, it is generally a case of «learning by doing». As a result, novice university teachers are likely to adapt traditional teacher-centered teaching styles, which are known to be ineffective for the development of complex competencies such as those measured by the CLA (Seidel \& Hoppert, 2011). At University of Jena, a postgraduate certificate in university teaching has been established to provide novice university teachers with systematic training based on principles of effective teacher professional development (Johannes, Fendler, \& Seidel, 2011). These principles include content focus, active learning, coherence between training and personal goals, appropriate duration, and collective participation as groups of learners.

We found that novice university teachers showed unspecific and general beliefs about teaching before embarking on the certification program (Johannes \& Seidel, 2012). For example, they described their knowledge of constructing assessments as 
rather low. After completing a workshop on the principles of test construction, they rated their most important learning experiences as having been introduced to methods of objective assessment, learned how to align instruction to learning outcomes, and developed an awareness of the responsibility that a teacher has when using an assessment. After completing the one-year certification program, the novice teachers had acquired basic knowledge and skills necessary for teaching, learned to adapt their own teaching goals to practice, and to align the assessment of outcomes to their instruction (Johannes et al., submitted). One of the major findings of our study is that novice university teachers in Germany undergo a learning process that is characterized by the specification of knowledge and by the realistic integration of knowledge, practice, and beliefs about teaching.

\section{Conclusions}

This comment on Richard J. Shavelson's contribution presenting the CLA as a prototype for assessing business-planning competence made two major points:

- First, developing an assessment such as the CLA requires high expertise in educational assessment as well as methodological and technical rigor. The CLA is based on a clear conceptualization of the construct of competence, its development was theory driven, and it uses frontline methods and analysis techniques. It can therefore serve as a prototype for many other areas of competence assessment beyond business education.

- Second, measuring university effectiveness is a valuable undertaking that is likely to remain a key point on the agenda of university reform. In the long run, however, assessment of learning outcomes can be truly effective only if it is combined with concepts and measures for professional development and reform, such as the systematic training and certification of novice university teachers.

\section{References}

Desimone, L. M. (2009). Improving impact studies of teachers' professional development: Toward better conceptualizations and measures. Educational Researcher, 38(3), 181-199

Johannes, C.; Fendler, J. \& Seidel, T. (2012). Teachers' perceptions of the learning environment and their knowledge base in a training program for novice university teachers. International Journal for Academic Development, 1-14

Johannes, C. \& Seidel, T. (2010). Professionelles Lernen von Anfängern in der Hochschullehre. Personalund Organisationsentwicklung in Einrichtungen der Lehre und Forschung, 2+3, 63-72

Johannes, C. \& Seidel, T. (2012). Professionalisierung von Hochschullehrenden: Lehrbezogene Vorstellungen, Wissensanwendung und Identitätsentwicklung in einem videobasierten Qualifikationsprogramm. Zeitschrift für Erziehungswissenschaft, 15(2), 233-251

OECD. (2010). Education at a glance. Paris: OECD

Seidel, T. \& Hoppert, A. (2011). Merkmale von Lehre an der Hochschule. Ergebnisse zur Gestaltung von Hochschulseminaren mittels Videoanalysen. Unterrichtswissenschaft, 39, 154-172 